\title{
Are ECG abnormalities in Noonan syndrome characteristic for the syndrome?
}

\author{
R. Raaijmakers • C. Noordam • J. A. Noonan • \\ E. A. Croonen - C. J. A. M. van der Burgt • \\ J. M. T. Draaisma
}

Received: 1 October 2007 / Accepted: 10 January 2008 / Published online: 13 February 2008

(C) The Author(s) 2008

\begin{abstract}
Of all patients with Noonan syndrome, 50-90\% have one or more congenital heart defects. The most frequent occurring are pulmonary stenosis (PS) and hypertrophic cardiomyopathy. The electrocardiogram (ECG) of a patient with Noonan syndrome often shows a characteristic pattern, with a left axis deviation, abnormal $\mathrm{R} / \mathrm{S}$ ratio over the left precordium, and an abnormal $\mathrm{Q}$ wave. The objective of this study was to determine if these ECG characteristics are an independent feature of the Noonan syndrome or if they are related to the congenital heart defect. A cohort study was performed with 118 patients from two university hospitals in the United States and in The Netherlands. All patients were diagnosed with
\end{abstract}

R. Raaijmakers $\cdot$ E. A. Croonen · J. M. T. Draaisma

Department of Paediatric Cardiology,

Radboud University Nijmegen Medical Centre,

Nijmegen, The Netherlands

C. Noordam

Department of Metabolic and Endocrine Disorders,

Radboud University Nijmegen Medical Centre,

Nijmegen, The Netherlands

\section{J. A. Noonan}

Department of Paediatric Cardiology,

University of Kentucky Medical Centre,

Lexington, KY, USA

\section{J. A. M. van der Burgt}

Department of Clinical Genetics,

Radboud University Nijmegen Medical Centre,

Nijmegen, The Netherlands

\section{R. Raaijmakers ( $\square)$}

Department of Paediatrics 833,

UMC St Radboud, P.O. Box 9101, 6500 HB Nijmegen,

The Netherlands

e-mail: r.raaijmakers@cukz.umcn.nl definite Noonan syndrome and had had an ECG and echocardiography. Sixty-nine patients $(58 \%)$ had characteristic abnormalities of the ECG. In the patient group without a cardiac defect $(n=21)$, ten patients had a characteristic ECG abnormality. There was no statistical relationship between the presence of a characteristic ECG abnormality and the presence of a cardiac defect $(p=0.33)$. Patients with hypertrophic cardiomyopathy had more ECG abnormalities in total $(p=0.05)$, without correlation with a specific ECG abnormality. We conclude that the ECG features in patients with Noonan syndrome are characteristic for the syndrome and are not related to a specific cardiac defect. An ECG is very useful in the diagnosis of Noonan syndrome; every child with a Noonan phenotype should have an ECG and echocardiogram for evaluation.

Keywords Noonan syndrome - Electrocardiography · Pulmonary artery stenosis $\cdot$ Hypertrophic cardiomyopathy

\author{
Abbreviations \\ PS Pulmonary artery stenosis \\ HCM Hypertrophic cardiomyopathy \\ ECG Electrocardiogram
}

\section{Introduction}

Noonan syndrome is a relatively common multiple congenital anomaly syndrome, the incidence being estimated by Nora et al. [19] between 1 per 1,000-2,500 live births. Mendez and Opitz [13] consider the frequency to be even higher, with 1 per 1,000 severely affected cases and 1 per 100 with mild expression. The syndrome was first described as a distinct syndrome in 1963 by Noonan and 
Ehmke [15] who reported 9 patients with Turner-like abnormalities but without the chromosomal pattern of Turner syndrome. NS may occur on a sporadic basis or in a pattern consistent with autosomal dominant inheritance. In 1994 a gene was localized at the long arm of chromosome 12 [9], and in 2001 the gene was identified as the PTPN11 gene [27]. About $50 \%$ of Noonan syndrome cases have PTPN11 mutations [25, 27]. PTPN11 encodes the nonreceptor protein tyrosine phosphatase SHP-2. This enzyme is involved in a wide variety of intracellular signal cascades and is required in several developmental processes $[14,25]$.

The main clinical features of Noonan syndrome are characteristic facial features, short stature, and several cardiac defects. Fifty to $90 \%$ of all Noonan patients have one or more cardiac malformations. Presented most frequently is pulmonary stenosis (pulmonary artery as well as pulmonary valve stenosis), described in $50-62 \%$ of cases $[11,17,22,24]$, while hypertrophic cardiomyopathy (HCM) occurs in $20-30 \%$ [1, 11]. Atrial and/or ventricular septal defects are mentioned in $5-15 \%$ of cases $[11,18,24]$. Some more rare malformations are coarctation of the aorta and structural mitral valve abnormalities [1, 12, 18]. Patients with a PTPN11 gene mutation more often have pulmonary stenosis, and patients without a PTPN11 gene mutation more often have hypertrophic cardiomyopathy $[10,26]$.

The electrocardiogram (ECG) of Noonan patients frequently shows a characteristic pattern (Fig. 1). Typical features mentioned are a left axis deviation with a negative aVF, abnormal R/S ratio over the left precordium, and an abnormal $\mathrm{Q}$ wave $[5,7,23]$. The cause of these characteristic ECG features is still unknown. In this study we quantify these characteristic ECG findings and evaluate if the ECG characteristics are an independent diagnostic entity, if they are related to the cardiac abnormalities found by echocardiography in these patients, or if they are related to the presence of a PTPN11 gene mutation in cases where gene analysis was performed.

\section{Patients and methods}

An initial cohort of 166 patients with Noonan syndrome from the United States (62 patients) and The Netherlands (104 patients) was included in this study. All patients were originally referred for suspected Noonan syndrome, short stature, or cardiac defect to the University Hospitals of Lexington, USA and Nijmegen, The Netherlands. The diagnosis of Noonan syndrome was based on previously published clinical criteria $[16,28]$ and confirmed by a paediatric cardiologist $(\mathrm{JN})$ or clinical geneticist (IvdB). From the original cohort all patients who had undergone both an ECG and an echocardiogram were selected. Patients who had had surgical repair of the cardiac defects before the available ECG was performed were excluded. In this way our final study population was formed, consisting of 118 patients ( $71 \%$ of the original cohort) of which there were 70 males and 48 females. The median birth year of the patients was 1985 (range 1930-1999). The median age at which the ECG was performed was 6 years (range 038 years). Thirty-six patients (31\%)were tested for a PTPN11 gene mutation, and in 26 patients a PTPN11 gene mutation was found.

The electrocardiograms were reviewed by a paediatric cardiologist who had no knowledge of the presence of a cardiac malformation. The following characteristics were scored:

1. Left axis deviation: a QRS axis less than the lower limit of normal for the patient's age according to Park [20].

2. An abnormal R/S ratio in V6: little R deflection over the left precordium with an $\mathrm{R} / \mathrm{S}$ ratio lower than the lower limits of normal and $\mathrm{R}$ voltage in $\mathrm{V} 5$ and $\mathrm{V} 6$ less than $50 \%$ of the mean according to Park and Guntheroth [8, 21].

3. Abnormal $\mathrm{Q}$ wave: a $\mathrm{Q}$ voltage greater than the upper limit of normal and wider than $0.04 \mathrm{~s}$ [8].

The data were collected in SPSS and Excel. Comparisons between patient groups were made using Fisher exact test, with a significance threshold of $p \leq 0.05$.
Fig. 1 A characteristic electrocardiogram of a 3-monthold male NS patient showing left axis deviation and little $\mathrm{R}$ deflection over the left precordium

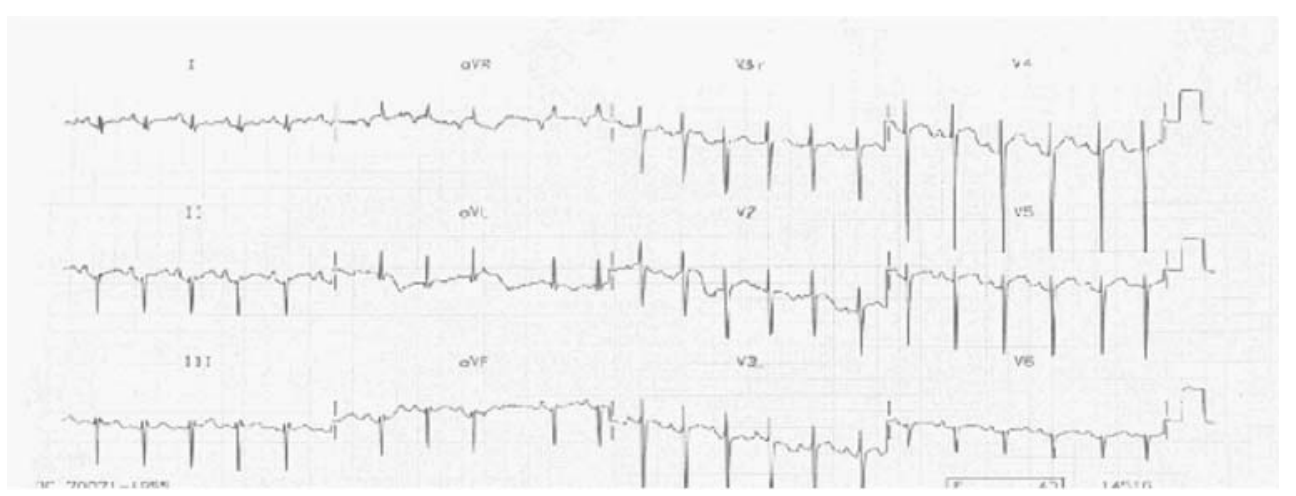


Table 1 Statistical analysis of the relationship between characteristic ECG abnormalities and cardiac defect/mutation Fisher exact test

\begin{tabular}{lllllll}
\hline & $\begin{array}{l}\text { Cardiac } \\
\text { defect }\end{array}$ & $\begin{array}{l}\text { No cardiac } \\
\text { defect }\end{array}$ & $\begin{array}{l}\text { Fisher } \\
p \text {-value }\end{array}$ & $\begin{array}{l}\text { Subgroup: } \\
\text { mutation }\end{array}$ & $\begin{array}{l}\text { Subgroup: no } \\
\text { mutation }\end{array}$ & $\begin{array}{l}\text { Fisher } \\
p \text {-value }\end{array}$ \\
\hline ECG abnormalities & 59 & 10 & 0.33 & 13 & 6 & 0.72 \\
No ECG abnormalities & 38 & 11 & & 13 & 4 & 1 \\
Left axis & 50 & 9 & 0.63 & 12 & 5 & \\
No left axis & 47 & 12 & & 14 & 5 & 0.48 \\
Little R & 22 & 2 & 0.24 & 1 & 1 & 0.48 \\
No little R & 75 & 19 & & 25 & 9 & 1 \\
Abnormal Q & 6 & 1 & 1 & 1 & 9 & \\
No Abnormal Q & 91 & 20 & & 25 & & \\
\hline
\end{tabular}

\section{Results}

One or more congenital heart defects were present in 97 of the 118 patients with Noonan syndrome. PS was present in 77 patients (65\%), HCM in 20 patients (17\%), and 12 patients $(10 \%)$ had other cardiac defects (mitral valve insufficiency, atrial septal defect, cleft mitral valve, aortic insufficiency, aortic valve malformation). Forty-five patients presented with more than one cardiac defect. Of the patients with more than one cardiac defect, 11 patients had PS in combination with HCM and 19 patients had PS in combination with atrial septal defect. There were 21 patients $(18 \%)$ without a congenital heart defect. Sixty-nine patients $(58 \%)$ had characteristic abnormalities of the ECG. Fifty-nine of them $(50 \%)$ had a left axis. Abnormal R/S ratio over the left precordium was found in 24 patients (20\%) and 7 patients had an abnormal Q-wave on ECG. Sixteen patients had two characteristic ECG abnormalities and three patients had all three characteristic ECG abnormalities.

In the 21 patients without a cardiac defect, ten had a characteristic ECG abnormality. No statistical differences in the occurrence of cardiac defects were seen between patients with or without a characteristic ECG abnormality (data not shown). There was no significant statistical correlation between a specific ECG abnormality and the presence of a cardiac defect, as is shown in Table 1. We also evaluated the possible relationship between ECG abnormalities and the most frequent cardiac defects, PS, and HCM. There was no significant statistical correlation between PS and one or more characteristic ECG abnormalities (Table 2). For HCM there was a significant positive correlation with the total of ECG abnormalities, but not with a specific ECG abnormality (Table 2).

In the patient group that was tested for the occurrence of a PTPN11 mutation (36 patients), no correlation was seen between a characteristic ECG abnormality and the presence or absence of a mutation (Table 1).

\section{Discussion}

In this study it is shown that ECG abnormalities found in patients with Noonan syndrome are characteristic for the syndrome. The presence of a congenital heart defect was statistically independent from one of the characteristic ECG features. Further, almost half of the patients without a demonstrable congenital heart disease had the characteristic ECG abnormalities for Noonan syndrome. However, the patients with HCM had an abnormal ECG significantly more often. In these patients this probably reflects the ventricular hypertrophy. We formed an original cohort of all referred patients for clinical suspicion of Noonan syndrome, short stature, and/or suspected cardiac defects to prevent bias due to patients referred only for cardiac reasons. However, some bias could still have occurred by
Table 2 Statistical analysis of the relationship between characteristic ECG abnormalities and pulmonary stenosis/hypertrophic cardiomyopathy

ECG electrocardiogram, Fisher Fisher exact test, $P S$ pulmonary stenosis, HCM hypertrophic cardiomyopathy

\begin{tabular}{lllllll}
\hline & PS & No PS & Fisher & HCM & No HCM & Fisher \\
\hline ECG abnormalities & 42 & 25 & 0.56 & 16 & 53 & 0.05 \\
No ECG abnormalities & 35 & 16 & & 4 & 45 & \\
Left axis & 34 & 25 & 0.12 & 12 & 47 & 0.46 \\
No left axis & 43 & 16 & & 8 & 51 & \\
Little R & 18 & 6 & 0.34 & 5 & 19 & 0.55 \\
No little R & 59 & 35 & & 15 & 79 & \\
Abnormal Q & 5 & 2 & 1 & 1 & 6 & 1 \\
No Abnormal Q & 72 & 39 & & 19 & 92 & \\
\hline
\end{tabular}


selecting the patients who had undergone both an ECG and echocardiography. Our patient group was representative in the occurrence of cardiac defects as previously described $[1,11,17,22,24]$, with $65 \%$ PS, $17 \% \mathrm{HCM}$, and $10 \%$ other defects in our cohort. There was no significant difference in occurrence of cardiac defects or characteristic ECG findings between the patients from The Netherlands and the patients from the United States (data not shown). With these results we assume there was no important bias in our patient group by referral or selection.

The patients in whom mutation analysis was performed did not significantly differ from the other patients with respect to ECG abnormalities (Table 1) or with respect to cardiac defects. In the genetically tested patients, no differences in ECG abnormalities were found, but significant differences were found with respect to the cardiac defects. In the patients with a mutation, none had HCM, as opposed to one third in the group without a mutation. This is in concordance with previous observations, in which HCM patients less often have a PTPN11 mutation $[8,9]$.

A typical electrocardiogram with a left axis and an abnormal R/S ratio over the left precordium was first described in Noonan patients in 1972 [7]. The electrocardiography was reported earlier as being useful in the diagnosis of HCM [6], and Van der Burgt et al. [28] proposed that a typical ECG can be of value in establishing the diagnosis of Noonan syndrome. The present study strongly supports this proposal.

The exact pathophysiology of the left QRS axis is still unknown, but a possible explanation could be a counterclockwise rotation of the heart in combination with a conduction defect abnormality $[2,3]$. There are very few data about the occurrence of one or more of these typical ECG findings in otherwise healthy children. Only the occurrence of a left axis deviation in healthy children has been studied more extensively. Calcaterra et al. [4] emphasize the unusual finding of a left axis deviation in normal children, with an incidence of $1.4 \%$. The other characteristic ECG findings have not been reported in healthy children in the literature to our knowledge. In this study we showed that the above-mentioned ECG characteristics occur in $58 \%$ of Noonan patients and that they are independent of the presence of a demonstrable heart disease. Therefore the ECG is a very useful, noninvasive and relatively simple diagnostic tool in the diagnosis of Noonan syndrome. Every child with Noonan phenotype should have an ECG and echocardiogram for evaluation.

Open Access This article is distributed under the terms of the Creative Commons Attribution Noncommercial License which permits any noncommercial use, distribution, and reproduction in any medium, provided the original author(s) and source are credited.

\section{References}

1. Allanson JE (1987) Noonan syndrome. J Med Genet 24:9-13

2. Armengol AJ, Brohet CR, Linterman JP, Vliers A (1987) Le ventricle guache dans le syndrome de Noonan. Aspects electrovecto-echo et angio-cardiographiques. Arch mal coeur vaiss 80:445-453

3. Bertola DR, Kim CA, Sugayama SM, Albano LM, Wagenfuhr J, Moyses RL, Gonzalez CH (2000) Cardiac findings in 31 patients with Noonan's syndrome. Arq Bras Cardiol 75:409-412

4. Calcaterra G, Puglisi R (1989) Left axis deviation in healthy infants and children. Int J Cardiol 24:236-238

5. Digilio MC, Marino B, Picchio F, Prandstraller D, Toscano A, Giannotti A, Dallapiccola B (1998) Noonan syndrome and aortic coarctation. Am J Med Genet 80:160-162

6. Duncan WJ, Fowler RS, Farkas LG, Ross RB, Wright AW, Bloom KR, Huot DJ, Sondheimer HM, Rowe RD (1981) A comprehensive scoring system for evaluating Noonan syndrome. Am J Med Genet 10:37-50

7. Ehlers KH, Engle MA, Levin AR, Deely WJ (1972) Eccentric ventricular hypertrophy in familial and sporadic instances of 46 XX, XY Turner phenotype. Circulation 45:639-652

8. Guntheroth WG (1965) Pediatric electrocardiography. Saunders, Philadelphia

9. Jamieson CR, van dB I, Brady AF, van Reen M, Elsawi MM, Hol F, Jeffery S, Patton MA, Mariman E (1994) Mapping a gene for Noonan syndrome to the long arm of chromosome 12. Nat Genet $8: 357-360$

10. Jongmans M, Sistermans EA, Rikken A, Nillesen WM, Tamminga R, Patton M, Maier EM, Tartaglia M, Noordam K, van dB I (2005) Genotypic and phenotypic characterization of Noonan syndrome: new data and review of the literature. Am J Med Genet A $134: 165-170$

11. Lin AE (1988) Noonan syndrome. J Med Genet 25:64-65

12. Marino B, Digilio MC, Toscano A, Giannotti A, Dallapiccola B (1999) Congenital heart diseases in children with Noonan syndrome: an expanded cardiac spectrum with high prevalence of atrioventricular canal. J Pediatr 135:703-706

13. Mendez HM, Opitz JM (1985) Noonan syndrome: a review. Am J Med Genet 21:493-506

14. Neel BG, Gu H, Pao L (2003) The 'Shp'ing news: SH2 domaincontaining tyrosine phosphatases in cell signaling. Trends Biochem Sci 28:284-293

15. Noonan JA, Ehmke A (1963) Associated noncardiac malformations in children with congenital heart disease. J Pediatr 468-469

16. Noonan JA (1994) Noonan syndrome. An update and review for the primary pediatrician. Clin Pediatr (Phila) 33:548-555

17. Noordam C, Thoonen G, van der Burgt CJ (2003) The Noonan syndrome from a pediatric perspective. Ned Tijdschr Geneeskd 147:644-648

18. Nora JJ, Lortscher RH, Spangler RD (1975) Echocardiographic studies of left ventricular disease in Ullrich-Noonan syndrome. Am J Dis Child 129:1417-1420

19. Nora JJ, Nora AH, Sinha AK, Spangler RD, Lubs HA (1974) The Ullrich-Noonan syndrome (Turner phenotype). Am J Dis Child 127:48-55

20. Park MK (1996) Pediatric cardiology for practitioners. Mosby, St Louis

21. Park MK, Guntheroth WG (1992) How to read pediatric ECGs. Mosby, St Louis

22. Pernot C, Marcon F, Worms AM, Cloez JL, Gilgenkrantz S, Marios L (1987) La dysplasie cardio-vasculaire du syndrome de Noonan. Arch Mal Coeur 80:434-443

23. Sanchez-Cascos A (1983) The Noonan syndrome. Eur Heart J 4:223-229 
24. Sharland M, Burch M, McKenna WM, Paton MA (1992) A clinical study of Noonan syndrome. Arch Dis Child 67:178-183

25. Tartaglia M, Cordeddu V, Chang H, Shaw A, Kalidas K, Crosby A, Patton MA, Sorcini M, van der Burgt I, Jeffery S, Gelb BD (2004) Paternal germline origin and sex-ratio distortion in transmission of PTPN11 mutations in Noonan syndrome. Am J Hum Genet 75:492-497

26. Tartaglia M, Kalidas K, Shaw A, Song X, Musat DL, van der Burgt I, Brunner HG, Bertola DR, Crosby A, Ion A, Kucherlapati RS, Jeffery S, Patton MA, Gelb BD (2002) PTPN11 mutations in Noonan syndrome: molecular spectrum, genotype-phenotype correlation, and phenotypic heterogeneity. Am J Hum Genet 70:1555-1563

27. Tartaglia M, Mehler EL, Goldberg R, Zampino G, Brunner HG, Kremer H, van der Burgt I, Crosby AH, Ion A, Jeffery S, Kalidas K, Patton MA, Kucherlapati RS, Gelb BD (2001) Mutations in PTPN11, encoding the protein tyrosine phosphatase SHP-2, cause Noonan syndrome. Nat Genet 29:465-468

28. van der Burgt I, Berends E, Lommen E, van Beersum S, Hamel B, Mariman E (1994) Clinical and molecular studies in a large Dutch family with Noonan syndrome. Am J Med Genet 53:187-191 